\title{
Advanced lesions of synchronous bilateral mammary Paget's disease: a case report
}

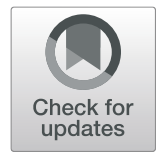

\author{
Lina Choridah', Wida Kartika Sari ${ }^{1}$, Ery Kus Dwianingsih² ${ }^{2}$, Irianiwati Widodo ${ }^{2}$, Suwardjo ${ }^{3}$ and \\ Sumadi Lukman Anwar ${ }^{3^{*}}$ (D)
}

\begin{abstract}
Background: Mammary Paget's disease is an eczematous eruption on the nipple and areola with underlying breast malignancy. It is often misinterpreted as chronic dermatitis or psoriasis causing a delayed diagnosis. Synchronous bilateral mammary Paget's disease is exceptionally rare and an advanced case with underlying invasive carcinoma might require long-term treatment and follow-up that could affect a patient's physical, psychological, and social aspects of well-being.

Case presentation: A 54-year-old Javanese woman presented in our clinic with a 2-year history of itching and chronic eczema in both areolae. Bilateral nipple retraction and retro-areolar palpable lumps were observed during the first presentation. Breast ultrasound revealed hypoechoic lesions in her left and right breasts. Mammograms showed an irregular hyperdense lesion and multiple microcalcifications. Histopathology from biopsy and bilateral mastectomy demonstrated infiltration of large Paget's cells in the epidermis of the areola with underlying lesions of invasive ductal carcinoma, diagnosed solid type with high nuclear grade and negative expression of estrogen receptor and progesterone receptor, with positive expression of human epidermal growth receptor-2(HER2) and Ki$67(45 \%)$.
\end{abstract}

Conclusions: In a patient with suspicious chronic inflammation of the nipple and areolae, prompt biopsy should be performed to avoid a delayed diagnosis of any malignant breast lesion.

Keywords: Paget's disease, Breast cancer, Areolae eczema, Bilateral synchronous, Delayed diagnosis

\section{Background}

Mammary Paget's disease presents as an eczema-like skin rash, with itching, ulceration, or scaly changes affecting the nipple and areola; it is frequently found with an underlying malignant tumor [1]. The disease is often incorrectly assumed to be atopic or contact dermatitis, psoriasis, or other benign dermatological lesions [1]. Around $90 \%$ of patients are diagnosed without a palpable mass during physical examination [1,2]. Diagnosis is established through full-thickness skin biopsy showing

\footnotetext{
*Correspondence: sl.anwar@ugm.ac.id

${ }^{3}$ Division of Surgical Oncology - Department of Surgery - Dr Sardjito Hospital/Faculty of Medicine, Public Health, and Nursing, Universitas Gadjah Mada, Jl Kesehatan No. 1, Yogyakarta 55281, Indonesia

Full list of author information is available at the end of the article
}

the invasion of epidermis by typical giant glandular epithelial cells with hyperchromatic nuclei known as Paget's cells $[1,2]$. The diagnosis is frequently developed through clinical findings; however, radiological imaging is required to detect the underlying carcinomas and to determine clinical staging for planning the further management $[1,2]$.

Paget's disease represents $1-3 \%$ of all breast cancers and the synchronous bilateral case is very uncommon [ 1 , 2]. In patients with an associated palpable mass, the concurrent tumor is likely to be an invasive carcinoma located in the center of the breast with axillary lymph node infiltration [2]. Therefore, patients with mammary Paget's disease with evidence of palpable mass most probably require both radical surgery and adjuvant

\section{$\triangle B M C$}

(c) The Author(s). 2020 Open Access This article is licensed under a Creative Commons Attribution 4.0 International License, which permits use, sharing, adaptation, distribution and reproduction in any medium or format, as long as you give appropriate credit to the original author(s) and the source, provide a link to the Creative Commons licence, and indicate if changes were made. The images or other third party material in this article are included in the article's Creative Commons licence, unless indicated otherwise in a credit line to the material. If material is not included in the article's Creative Commons licence and your intended use is not permitted by statutory regulation or exceeds the permitted use, you will need to obtain permission directly from the copyright holder. To view a copy of this licence, visit http://creativecommons.org/licenses/by/4.0/ The Creative Commons Public Domain Dedication waiver (http://creativecommons.org/publicdomain/zero/1.0/) applies to the data made available in this article, unless otherwise stated in a credit line to the data. 
treatment $[3,4]$. Because the initial appearance resembles benign skin lesions, diagnosis of mammary Paget's disease is often delayed [3-5]. In low-income and middle-income countries, including Indonesia, the delay in diagnosis is even longer due to the relatively low level of cancer awareness and limited health facilities [6, 7]. In a case of bilateral Paget's disease with associated invasive carcinomas and lymph node infiltration, bilateral mastectomy and subsequent adjuvant local and systemic treatment remain the preferred treatment choice $[3,4]$. In addition, positive family history and genetic predisposition are independent risk factors of synchronous bilateral breast cancer [8]. Therefore, psychosocial support and multidisciplinary rehabilitation are highly recommended to promote emotional and behavioral adaptation after the acute treatment. We reported a case of synchronous bilateral mammary Paget's disease who underwent bilateral MRMs.

\section{Case presentation}

A 54-year-old Javanese woman presented to our hospital with a 2-year history of non-healing scaly rash and itching in both nipples and areolae without any family history of breast or ovarian cancer. She was previously examined by general practitioners as well as a dermatologist and received anti-allergy topical treatment before undergoing a biopsy. On physical examination, eczema, excoriation, and ulceration of both nipples and areola were observed with right nipple retraction and no obvious nipple discharge (Fig. 1). Irregular firmly formed retro-papilla lumps of size $2 \times 2 \mathrm{~cm}$ and $1 \times 2 \mathrm{~cm}$ were palpated in her right and left breasts, respectively. No palpable axillary lymph node was observed in the bilateral axillae. Ultrasonography of both breasts showed a spiculated hypoechoic lesion with calcification measuring around $1.61 \times 2.06 \times 1.78 \mathrm{~cm}$ in the right retropapilla and an amorphic, irregular lesion measuring $0.82 \times 0.67 \times 1.73 \mathrm{~cm}$ located in the left retro-papilla (Fig. 2). Both lesions were categorized as Breast Imaging Reporting and Data System (BIRADS) IV (Fig. 3). Mammograms showed an amorphic hyperdense lesion measuring around $1.26 \times 2.12 \mathrm{~cm}$ that was centrally located approximately $1.75 \mathrm{~cm}$ in the right nipple and multiple retro-papillae microcalcifications in her left breast (Fig. 3). A histopathological examination showed typical Paget's disease of the bilateral breasts with underlying invasive ductal carcinoma, diagnosed as high grade with lymphovascular invasion (Fig. 4). Pathological staging was pT2 pN1 cM0 for the right breast and pT1 pN0 cM0 for the left breast. Immunostaining showed negative expression of estrogen receptor (ER) and progesterone receptor (PR) and positive expression of human epidermal growth receptor-2 (HER2) and Ki-67 (45\%) (Fig. 5). Our patient underwent bilateral modified radical mastectomies (MRMs) and completed the self-reported questionnaires of Indonesian adapted European Organisation for Research and Treatment of Cancer (EORTC) Quality of Life questionnaire (QLQ)-C30 [9] and QLQBR23.

\section{Discussion}

Mammary Paget's disease is a rare clinical pathology of the nipple and areolae and often presents in conjunction with an underlying breast carcinoma $[1,10]$. Early manifestation might present as scaling or redness that is often misinterpreted as eczema or chronic inflammatory reaction causing a delayed diagnosis $[1,11]$. Round plaque with eczema-like rash and ulceration limited to the

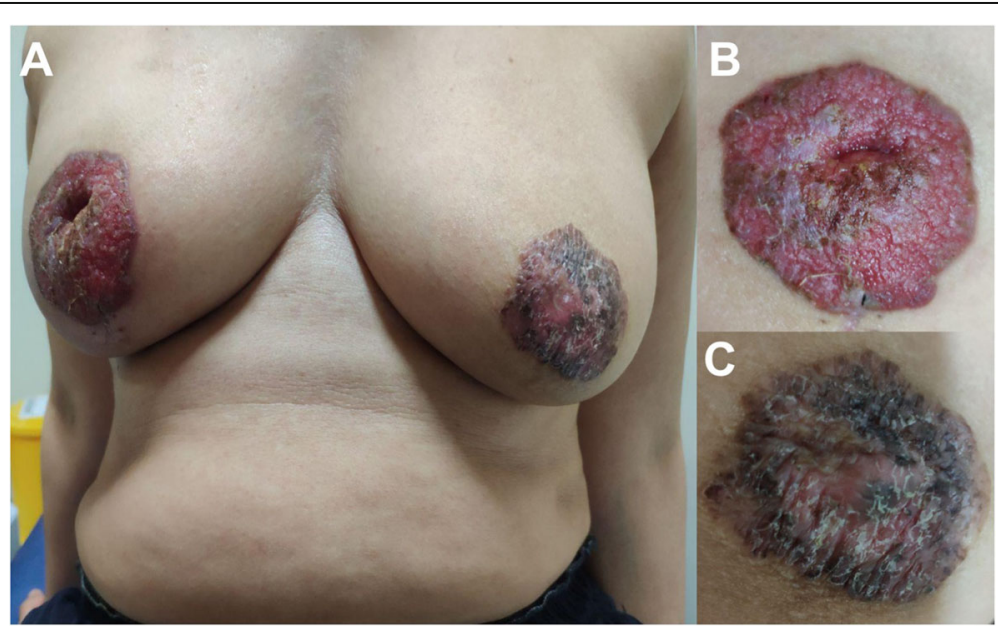

Fig. 1 Clinical presentation at diagnosis. a Clinical image showing synchronous bilateral mammary Paget's disease. b Right nipple-areolae complex showing ulceration in the central area and an eczematous scaly lesion. c Left nipple-areolae complex showing an eczematous, pigmented, scaly lesion 

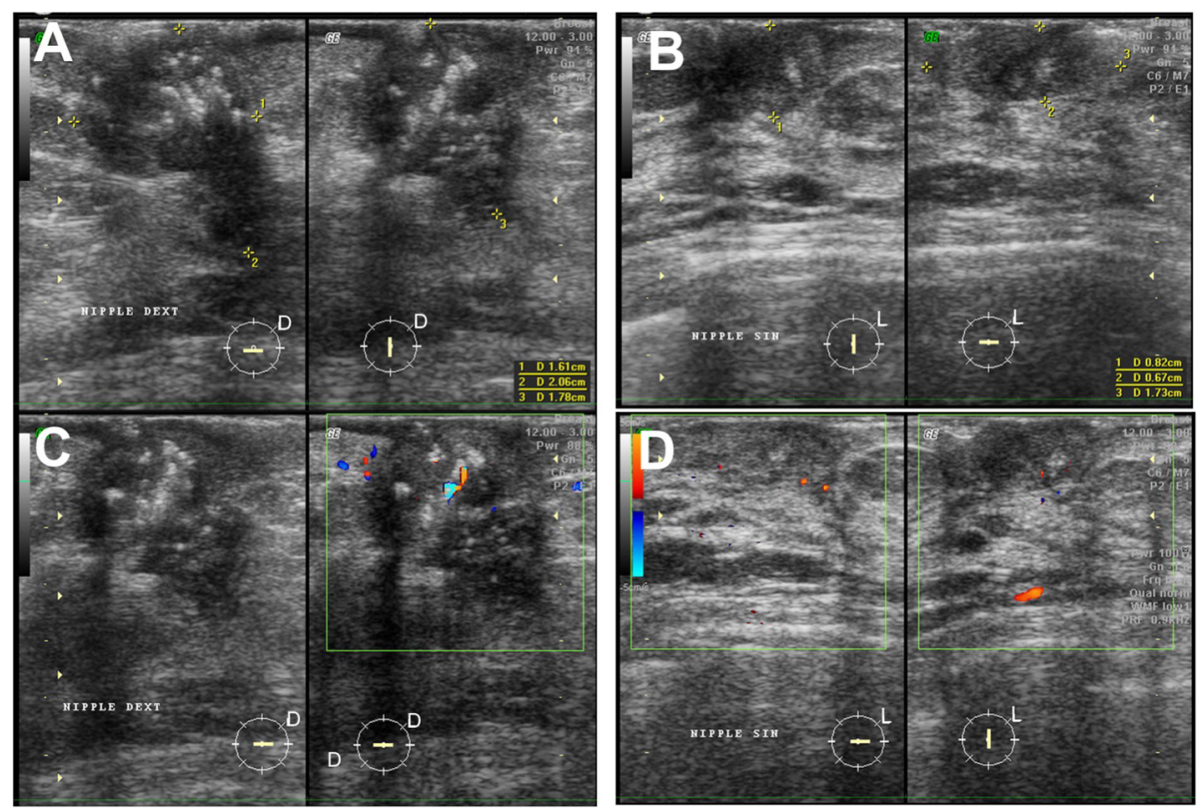

Fig. 2 Ultrasound images showing hypoechoic lesion with calcification measuring around $1.61 \times 2.06 \times 1.78 \mathrm{~cm}$ at right retro-papilla (a) and an amorphic, irregular lesion measuring $0.82 \times 0.67 \times 1.73 \mathrm{~cm}$ located at the left retro-papilla $(\mathbf{b})$ with relative hypervascularization at the right and left nipple-areolae complexes (c, d, respectively)

areolae with or without bloody/serous discharge represent an advanced lesion of Paget's disease [1, 11]. It is often accompanied by inversion or retraction of the nipple. A unilateral lesion is mostly found whereas the synchronous bilateral case is very uncommon. Several benign skin lesions that often cause misinterpretation of mammary Paget's disease as well as common clinical manifestations that can be used to differentiate it from benign inflammatory skin lesions are summarized in Table 1. We report the case of a patient with advanced lesions of bilateral mammary Paget's disease and concomitant palpable masses (Figs. 1, 2 and 3). Delayed diagnosis is associated with multiple factors including patient delay (lack of knowledge and awareness, use of traditional therapy, fear of treatment, financial constraints, competing life priority, and embarrassment of
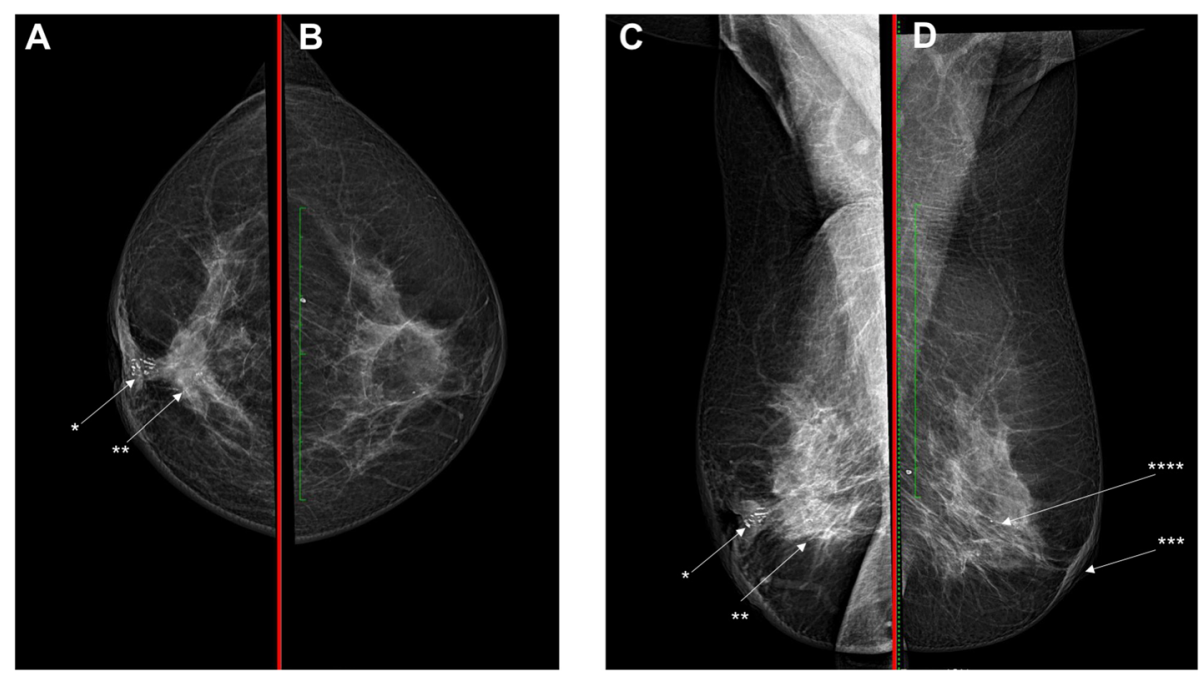

Fig. 3 Images of mammograms ( $\mathbf{a}, \mathbf{b}$ craniocaudal views; $\mathbf{c}$, $\mathbf{d}$ mediolateral oblique views). Mammograms of the right breast (a and $\mathbf{c}$ ) show an amorphic hyperdense lesion measuring around $1.26 \times 2.12 \mathrm{~cm}$ which was centrally located approximately $1.75 \mathrm{~cm}$ from the right nipple $(* *)$ and multiple microcalcifications $\left({ }^{*}\right)$. Mammograms of the left breast (b and $\left.\mathbf{d}\right)$ show skin thickening $\left(^{* *}\right)$ and retro-papillae multiple microcalcifications $\left({ }^{* * * *}\right)$ 

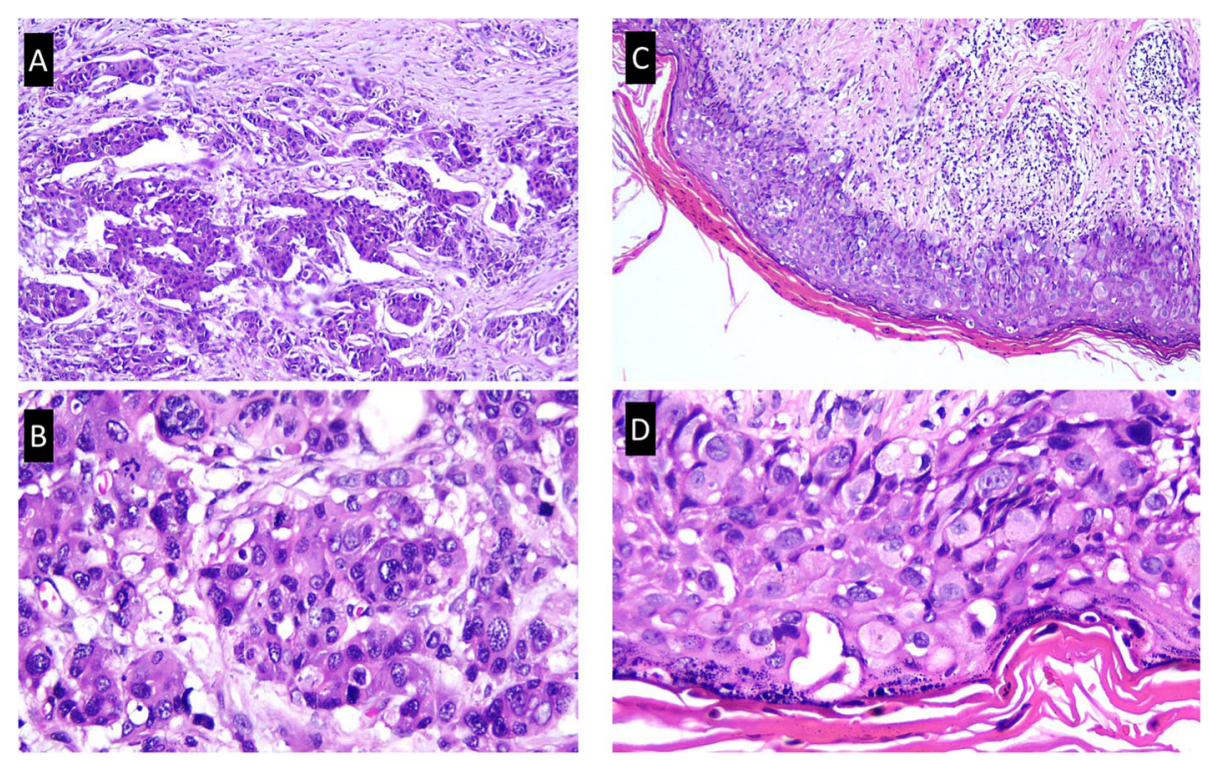

Fig. 4 Nests of tumor cells, infiltrating surrounding fibrous tissue (hematoxylin and eosin staining). a Tumor nests of the main breast mass $(\times 100$ magnification]. b Tumor cells are pleomorphic, large size, with vesicular and hyperchromatic nuclei ( $\times 200$ magnification). c Skin epidermis is infiltrated by numerous tumor cells which resemble the main lesion ( $\times 100$ magnification). $\mathbf{d}$ Characteristics of the tumor cells are similar to $\mathbf{b}$ $(\times 200$ magnification)

breast cancer diagnosis) and system delay (complicated referral system, appointment delay, misdiagnosis, misinterpretation of mammography or diagnostic tests, and limited health facilities) [12]. Both factors might have influenced the delayed diagnosis in our case, therefore, further study is required to identify determinants causing delayed diagnosis of breast cancer in Indonesia.
Any suspected Paget's disease should be further assessed with radiological imaging because of its high association with in situ or invasive breast carcinoma [13]. Imaging is very important to determine the suitable option for surgery as well as the adjuvant treatment [13]. Breast ultrasonography is useful particularly if it is used in combination with mammography [14]. Breast ultrasonography is able to detect any hypoechoic area,

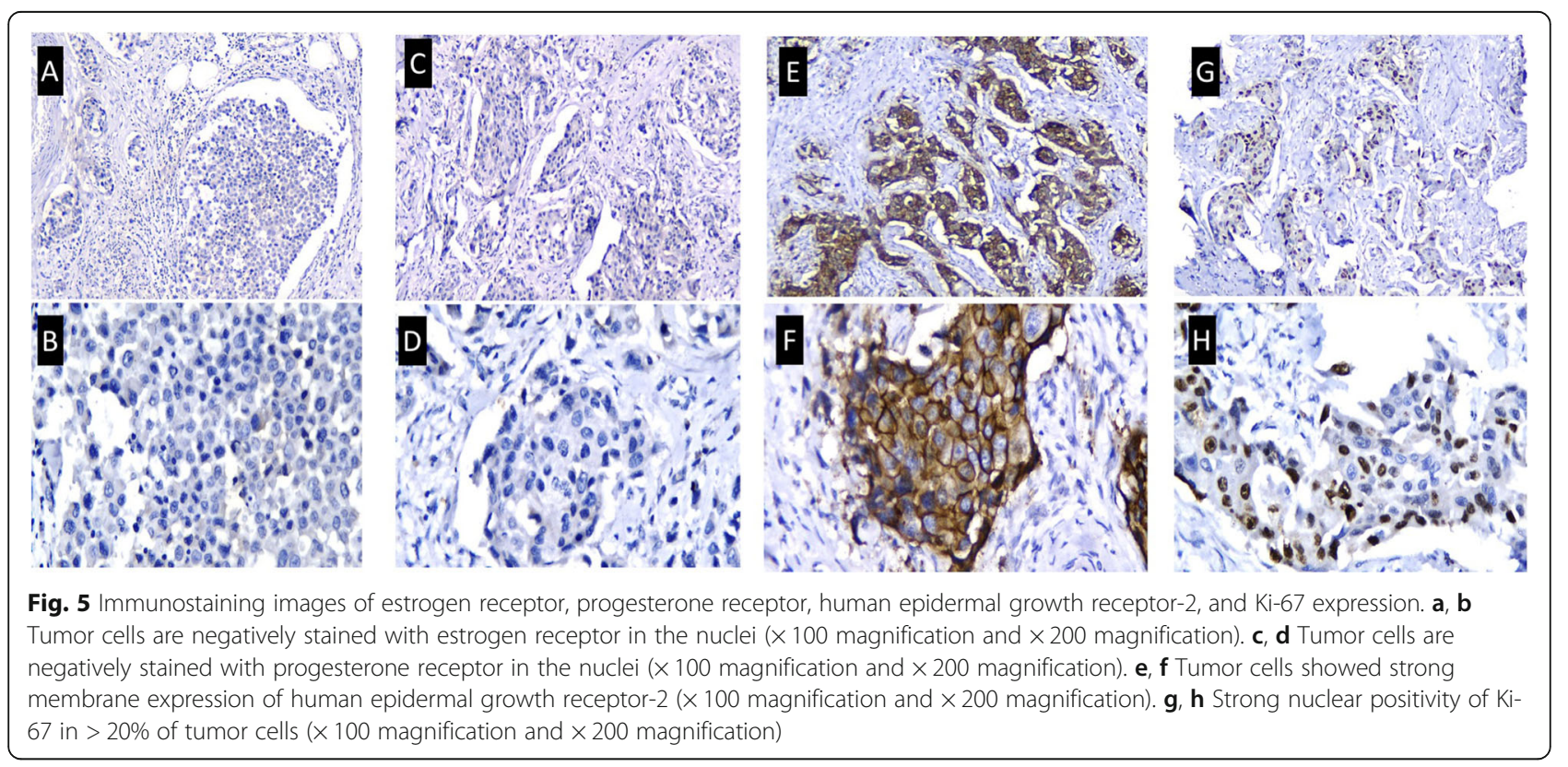


Table 1 Benign skin and mammary lesions that often cause misinterpretation with mammary Paget's disease

\begin{tabular}{lll}
\hline $\begin{array}{l}\text { Differential diagnosis of } \\
\text { mammary Paget's } \\
\text { disease }\end{array}$ & Clinical manifestations of mammary Paget's disease and benign inflammatory skin lesions in the nipple \\
\cline { 2 - 3 } Eczema & Paget's disease & Benign inflammatory skin lesions in the nipple \\
Psoriasis & No vesicles or pustules & Itchy \\
Irritant contact dermatitis & Nipple retraction or deformation & Vesicles and pustules \\
Mammary duct ectasia & Usually unilateral & No change in the nipple, limited in areolae lesions \\
Drug eruption & Sometimes with palpable lump & Bilateral \\
Toker cells & Older age & No lump \\
Nipple duct adenoma & Mammographic lesions/microcalcifications & Younger age \\
\hline
\end{tabular}

The second column lists some clinical manifestations that can be used to differentiate benign nipple areola inflammation from mammary Paget's disease

discrete mass, heterogeneous parenchyma, skin thickening, and dilated ducts which are mostly nonspecific findings with signs of infection [14]. In addition, bilateral mammograms are very important to detect an underlying lesion including a mass or cluster of microcalcifications, to exclude multifocal carcinomas, as well as to evaluate the contralateral breast. Other presentations of mammary Paget's disease are thickening of skin, nipple, and areolae as well as nipple retraction, subareolar microcalcification, discrete mass, and architectural distortion [5, 13-15]. Although a mammogram is not always able to detect the underlying ductal carcinoma in situ (DCIS), the sensitivity is particularly higher in patients with palpable mass [13]. We revealed underlying tumors in the bilateral breasts using sonography and mammography in a patient with synchronous bilateral Paget's disease (Figs. 2 and 3). Breast magnetic resonance imaging (MRI) is considered superior to detect the underlying malignancy in Paget's disease because of its ability to better demonstrate abnormal enhancement or thickening of the nipple-areolar complex, as well as an enhancing in situ or invasive tumor including in a clinically unpalpable mass [13]. However, MRI is not always widely available in low-income and middle-income countries and referral for MRI examination is usually made only in occult disease after careful assessment of clinical and mammogram evaluations.

In Paget's disease, the main characteristic of histopathological examination is the presence of intraepidermal Paget's cells, which are glandular epithelial cells with a large clear cytoplasm and enlarged hyperchromatic nuclei that are often found in a basal layer without any intercellular bridges to the adjacent cells $[1,2]$. Expression levels of hormonal receptors, HER2, and Ki-67 vary among cases $[1,2]$. Expression of ER and PR was negative and expression of HER2 was positive in our reported case. HER2 protein expression is associated with the capability to promote cell motility and intraepithelial spread [16]. In addition, the patient might be eligible for future therapy targeted therapy to HER2.
Surgery remains the mainstay of mammary Paget's disease treatment. Mastectomy or subcutaneous mastectomy with or without axillary dissection has been practiced as a standard procedure. However, the current trend has shown the increased implementation of breast-conserving therapy for Paget's disease with comparable clinical outcomes particularly in the cases with DCIS or without underlying tumor [3]. With the availability of sentinel node biopsy and radiotherapy, conservation surgery for mammary Paget's disease has gained more interest [3]. In our case, we performed bilateral MRM because of the underlying invasive carcinomas in the bilateral breasts, unavailability of sentinel node biopsy, and potential long queue for radiotherapy. However, double mastectomies might result in a permanent change of appearance and body image of a woman. As the breasts represent femininity, beauty, motherhood, and women's identity in Indonesian and many other cultures, the perceived loss might cause negative impacts on both physical and psychosocial aspects of well-being. Quality of life measurement using a self-reported questionnaire showed that our patient had lower scores in the global health status, and cognitive and social functioning domains compared to the reference scores of patients with breast cancer [17]. In addition, our patient had lower scores in future perspective and sexual functioning but higher scores in the symptom scales compared to the references [18]. Although several factors contribute to a patient's quality of life score, including social-economic status, education, and the method of measurement, a selfreported questionnaire enables quick detection of an individual's response to treatment and current state of wellbeing. Meeting the psychosocial needs of a patient over the course of treatment and surveillance is recommended to improve the patient's acceptance, adherence to therapy, as well as their overall quality of life and well-being.

\section{Conclusion}

Although the presentation of mammary Paget's disease is rare, any suspected signs or symptoms of eczematoid, 
pigmented, crusted, or scaly lesions or chronic inflammation in the nipple or areolae should be confirmed with biopsy to avoid delayed diagnosis. In particular, in Indonesia, further public health actions are therefore required to improve breast cancer awareness as well as to strengthen the current health system for better breast cancer management.

\section{Abbreviations}

BIRADS: Breast Imaging Reporting and Data System; DCIS: Ductal carcinoma in situ; ER: Estrogen receptor; EORTC: European Organisation for Research and Treatment of Cancer; HER2: Human epidermal growth receptor-2; MRI: Magnetic resonance imaging; MRM: Modified radical mastectomy; PR: Progesterone receptor; QLQ: Quality of Life questionnaire

\section{Acknowledgements}

Not applicable.

\section{Authors' contributions}

LC, WKS, EKD, and IW prepared and collected the relevant test results. LC and WKS analyzed the imaging results, EKD and IW analyzed the histopathology tests, S and SLA collected the clinical data and follow-up. SLA wrote the first draft and finalized the manuscript. All authors read and approved the final version of the manuscript.

\section{Funding}

SLA was awarded grants by the Ministry of Research and Technology Republic of Indonesia PPUPT (Nr 2274/2019), FKKMK-UGM Dana Masyarakat (Nr 1499/2019), UGM-RTA (Nr133/2607-2020) and NUS-UGM-Tahir Foundation $(\mathrm{Nr}$ 1/2020).

\section{Availability of data and materials}

The clinical and imaging data supporting the analysis and findings of this study will be available from the corresponding author upon reasonable request.

\section{Ethics approval and consent to participate}

Not applicable.

\section{Consent for publication}

Written informed consent was obtained from the patient for the publication of this case report and any accompanying images. A copy of the written informed consent is available for review by the Editor-in-Chief of this journal.

\section{Competing interests}

All authors have declared that they have no potential competing interests.

\section{Author details}

'Department of Radiology, Dr Sardjito Hospital/Faculty of Medicine, Public Health, and Nursing, Universitas Gadjah Mada, Yogyakarta 55281, Indonesia. ${ }^{2}$ Department of Anatomical Pathology, Dr Sardjito Hospital/Faculty of Medicine, Public Health, and Nursing, Universitas Gadjah Mada, Yogyakarta 55281 , Indonesia. ${ }^{3}$ Division of Surgical Oncology - Department of Surgery Dr Sardjito Hospital/Faculty of Medicine, Public Health, and Nursing, Universitas Gadjah Mada, JI Kesehatan No. 1, Yogyakarta 55281, Indonesia.

Received: 25 April 2019 Accepted: 30 June 2020

Published online: 04 August 2020

\section{References}

1. Tan AR. Cutaneous manifestations of breast cancer. Semin Oncol. 2016;43(3): 331-4. https://doi.org/10.1053/.jseminoncol.2016.02.030.

2. Sandoval-Leon AC, Drews-Elger K, Gomez-Fernandez CR, Yepes MM, Lippman ME. Paget's disease of the nipple. Breast Cancer Res Treat. 2013; 141(1):1-12. https://doi.org/10.1007/s10549-013-2661-4.

3. Wong SM, Freedman RA, Stamell E, Sagara Y, Brock JE, Desantis SD, et al. Modern trends in the surgical management of Paget's disease. Ann Surg Oncol. 2015;22(10):3308-16. https://doi.org/10.1245/s10434-015-4664-3.
4. Yim JH, Wick MR, Philpott GW, Norton JA, Doherty GM. Underlying pathology in mammary Paget's disease. Ann Surg Oncol. 1997;4(4):287-92. https://doi.org/10.1007/BF02303576.

5. Müller CSL, Körner R, Takacs FZ, Solomayer EF, Vogt T, Pfoehler C. Metastatic breast carcinoma mimicking a sebaceous gland neoplasm: a case report. J Med Case Rep. 2011;5:428. https://doi.org/10.1186/1752-1947-5-428.

6. Anwar SL, Tampubolon G, Van Hemelrijck M, Hutajulu SH, Watkins J, Wulaningsih W. Determinants of cancer screening awareness and participation among Indonesian women. BMC Cancer. 2018;18(1):208. https://doi.org/10.1186/s12885-018-4125-z.

7. Anwar SL, Adistyawan G, Wulaningsih W, Gutenbrunner C, Nugraha B. Rehabilitation for cancer survivors: how we can reduce the healthcare service inequality in low- and middle-income countries. Am J Phys Med Rehabil. 2018;97(10):764-71. https://doi.org/10.1097/PHM. 0000000000000982.

8. Chen JJ, Wang Y, Xue JY, Chen Y, Chen YL, Xiao Q, et al. A clinicopathological study of early-stage synchronous bilateral breast cancer: a retrospective evaluation and prospective validation of potential risk factors. PLoS One. 2014;9(4):e95185. https://doi.org/10.1371/journal.pone. 0095185.

9. Perwitasari DA, Atthobari J, Dwiprahasto I, Hakimi M, Gelderblom H, Putter $\mathrm{H}$, et al. Translation and validation of EORTC QLQ-C30 into Indonesian version for cancer patients in Indonesia. Jpn J Clin Oncol. 2011;41(4):519-29. https://doi.org/10.1093/jjco/hyq243.

10. Dominici LS, Lester S, Liao GS, Guo L, Specht M, Smith BL, et al. Current surgical approach to Paget's disease. Am J Surg. 2012;204(1):18-22. https:// doi.org/10.1016/j.amjsurg.2011.07.010.

11. Sakorafas GH, Blanchard K, Sarr MG, Farley DR. Paget's disease of the breast. Cancer Treat Rev. 2001;27(1):9-18.

12. Maghous A, Rais F, Ahid S, Benhmidou N, Bellahamou K, Loughlimi H, et al. Factors influencing diagnosis delay of advanced breast cancer in Moroccan women. BMC Cancer. 2016;16:356. https://doi.org/10.1186/s12885-016-2394-y.

13. Sripathi S, Ayachit A, Kadavigere R, Kumar S, Eleti A, Sraj A. Spectrum of imaging findings in Paget's disease of the breast-a pictorial review. Insights Imaging. 2015;6:419-29. https://doi.org/10.1007/s13244-015-0415-z.

14. Günhan-Bilgen I, Oktay A. Paget's disease of the breast: clinical, mammographic, sonographic and pathologic findings in 52 cases. Eur J Radiol. 2006;60(2):256-63. https://doi.org/10.1016/j.ejrad.2006.06.010.

15. Fouad D. Paget's disease of the breast in a male with lymphomatoid papulosis: a case report. J Med Case Rep. 2011;5(43) https://doi.org/10.1186/ 1752-1947-5-43.

16. Sek P, Zawrocki A, Biernat W, Piekarski JH. HER2 molecular subtype is a dominant subtype of mammary Paget's cells. An immunohistochemical study. Histopathology. 2010;57(4):564-71. https://doi.org/10.1111/j.13652559.2010.03665.x.

17. Scott NW, Fayers PM, Aaronson NK, Bottomley A, de Graeff A, Groenvold M, et al. EORTC QLQ-C30 reference values. www.groups. EORTC.be. 2008.

18. Chen Q, Li S, Wang M, Liu L, Chen G. Health-related quality of life among women breast cancer patients in eastern China. Biomed Res Int. 2018;2018: 1-12. https://doi.org/10.1155/2018/1452635.

\section{Publisher's Note}

Springer Nature remains neutral with regard to jurisdictional claims in published maps and institutional affiliations.

Ready to submit your research? Choose BMC and benefit from:

- fast, convenient online submission

- thorough peer review by experienced researchers in your field

- rapid publication on acceptance

- support for research data, including large and complex data types

- gold Open Access which fosters wider collaboration and increased citations

- maximum visibility for your research: over $100 \mathrm{M}$ website views per year

At BMC, research is always in progress.

Learn more biomedcentral.com/submissions 